\title{
Programmed Cell Death Protein 4 -Expression in Urologic Tumors
}

\author{
Nicolas Fischer ${ }^{1}$, Friederike Göke ${ }^{2}$, Philip Kahl ${ }^{2}$, Vera Splittstößer ${ }^{3}$, Brigitte Lankat-Buttgereit ${ }^{4}$, \\ Stefan C. Müller ${ }^{3}$ and Jörg Ellinger ${ }^{3, *}$ \\ ${ }^{I}$ Department of Urology, Helios Clinic Krefeld, Germany \\ ${ }^{2}$ Department of Pathology, University Hospital Bonn, Germany \\ ${ }^{3}$ Department of Urology, University Hospital Bonn, Germany \\ ${ }^{4}$ Department of Internal Medicine, University Hospital Marburg, Germany
}

\begin{abstract}
Introduction: To investigate the role of the tumor suppressor gene Pdcd4 (programmed cell death 4) in benign and malignant prostate tissue specimen.

Materials and Methodology: Pdcd4 immunohistochemical expression was investigated in 73 prostate cancer and 14 normal tissues. The expression levels were correlated with clinicopathological parameters.

Results: Both, cytoplasmic and nuclear Pdcd4 staining was significantly decreased in malignant prostate tissue. Furthermore, Pdcd4 expression decreased with histopathological progression of the tumor. Receiver operating characteristic analyses showed in core staining results high sensitivity (83.3\%) and specificity (93.8\%) for the discrimination of prostate cancer from non-malignant tissue.

Conclusion: Our data support a role for Pdcd4 in prostate carcinogenesis. Pdcd4 immunohistochemical staining turns out to be a possible diagnostic marker for differentiation of prostate carcinoma and benign prostate tissue.
\end{abstract}

Keywords: Pdcd4, prostate cancer, apoptosis, immunohistochemistry.

\section{INTRODUCTION}

Programmed cell death $4(\operatorname{Pdcd} 4)$ is a tumor suppressor gene, which is known to be down-regulated in many tumor entities. It binds to the eukaryotic translation initiation factors eIF4A and eIF4G and inhibits their function by preventing RNA binding (AP-1 transactivation) $[1,2]$. The Pdcd4 gene is located on chromosome 10q24 and encodes a 469 aminoacids long protein with two basic domains on the $\mathrm{C}-$ and N- terminus and two conserved alpha-helical MA-3 domains. A major regulator of Pdcd4 expression, miR-21 is induced by the TGF- $\beta$ pathway. The $3^{6}$-UTR region of the Pdcd4 mRNA is a target of the miR-21. High miR-21 concentrations lead to a down-regulation of Pdcd4 and an induction of metastasis, invasion and intravasation in cell culture [3]. In Pdcd4 over-expressing cells, the subsequent carbonic anhydrase II down-regulation shows its influence on the translational level [4]. At the transcriptional level Pdcd4 influences motifs of the promoter of the uPAR gene via phosphorylation of the $\mathrm{Sp}$ transcription factors in colorectal cells the $\mathrm{Sp} 1$ (specificity protein 1)/Sp3 [5]. Interestingly, this pathway is not confirmed for breast

*Address correspondence to this author at the Department of Urology, University of Bonn. Sigmund-Freud-Strasse 25, 53127 Bonn, Germany; Tel: ++49 228287 14249; Fax: ++49 228287 19150;

E-mail: joerg.ellinger@ukb.uni-bonn.de cancer: the lack of suppression of uPAR transcription by Pdcd4 overexpression therefore shows a possible tissue specific role of Pdcd4 and its involvement in carcinogenesis [6].

\section{MATERIAL AND METHODOLOGY}

\section{Patients}

We used tissue microarrays to study the nuclear and cytoplasmic expression pattern of Pdcd4 in malignant and benign prostate tissue. The tissue microarray included 87 prostate tissue samples: prostate cancer $n=73$, benign prostate tissue $\mathrm{n}=14$; see Table $\mathbf{1}$ for the detailed clinicopathological information. Tissue samples were derived from patients undergoing radical prostatectomy, respectively from patients with benign prostate hyperplasia undergoing transurethral resection of the prostate at the Department of Urology at the University Hospital Bonn in Germany. The study was approved by the local ethics committee (vote 199/10).

\section{Microarray Construction and Immunohistochemistry}

All specimens were fixed in $4 \%$ buffered formalin and embedded in paraffin wax. Serial histological sections $4 \mu \mathrm{m}$ thick were cut from the paraffin blocks and stained with 
haematoxylin/eosin. The original diagnosis was confirmed in all cases by an independent pathologist. Tumor and benign regions were marked on the slides, and three cores were taken out of the paraffin block and transferred into a recipient block. Pdcd4 immunohistochemical staining was done automatically (DAKO TechMate 500, DAKO, Glostrup, Danmark) according to the manufacturer's instructions. The anti-Pdcd4 antibody was purchased from Rockland Immunochemicals (Philadelphia, USA) and used at a 1:400 concentration. Negative controls were run concurrently using rabbit igG-isotype. In malignant samples, inflammatory cells, positive stromal cells and normal tissue, all with a high Pdcd4 expression pattern served as an internal control.

Pdcd4 expression was scored by one pathologist who was unaware of the patients' clinical history. As described by Mudduluru et al. nuclear and cytoplasmic immunoreactions were evaluated [7]: Pdcd4 staining quantity was classified in four groups according to the percentage of positively stained nuclei/cytoplasm: score 0 , none; score $1, \leq 30 \%$; score 2,30 $70 \%$; score $3, \geq 70 \%$. In addition, a Pdcd 4 intensity score was determined for cytoplasmic and nuclear expression: score 0 , none; score 1 , weak; score 2 , intermediate; score 3 , strong. In addition, a total Pdcd4 expression score was calculated as the sum of the nuclear and cytoplasmic scores for intensity and quantity respectively. All cases were divided into four groups: negative/none (score 0 ), weak/low (score 1 or 2 ), intermediate/medium (score 3 or 4) and strong staining (score 5 or 6 ). All images were captured using a pathology scanner (Pannoramic MIDI Scanner, 3DHISTECH, Budapest, Hungary). A representative immunohistochemical staining is shown in Fig. (1A) (benign prostate tissue) and Fig. (1B) (prostate cancer).

\section{Statistical analysis}

Clinicopathological parameters were correlated with Pdcd4 expression using the chi-square-test. Receiver operating characteristics analyses were used to determine the diagnostic information of Pdcd4 expression for the differentiation of prostate cancer and benign prostate tissue. All statistical analyses were done using the Statistical Package for the Social Sciences 20 (IBM Corporation, Somer NY, USA). Significance was concluded at $\mathrm{p}<0.05$.

\section{RESULTS}

The nuclear Pdcd4 staining was significantly decreased in prostate cancer tissue $(p<0.001$, see Table 2). Mean
A

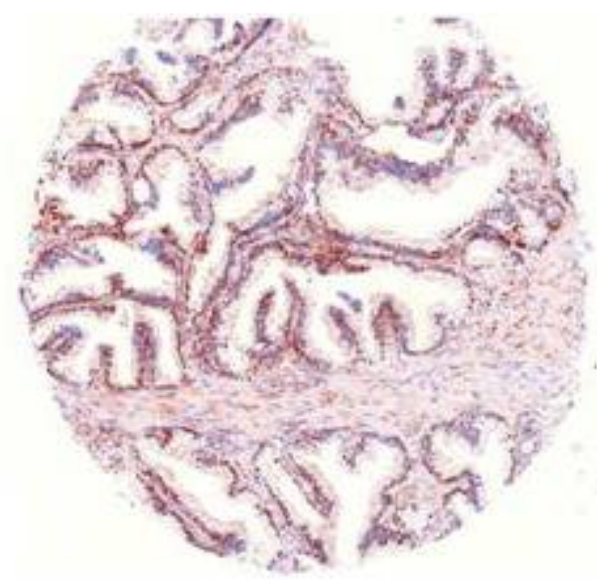

B

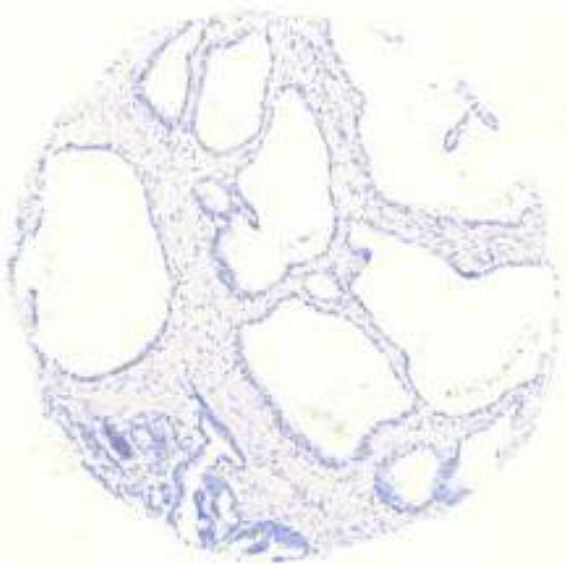

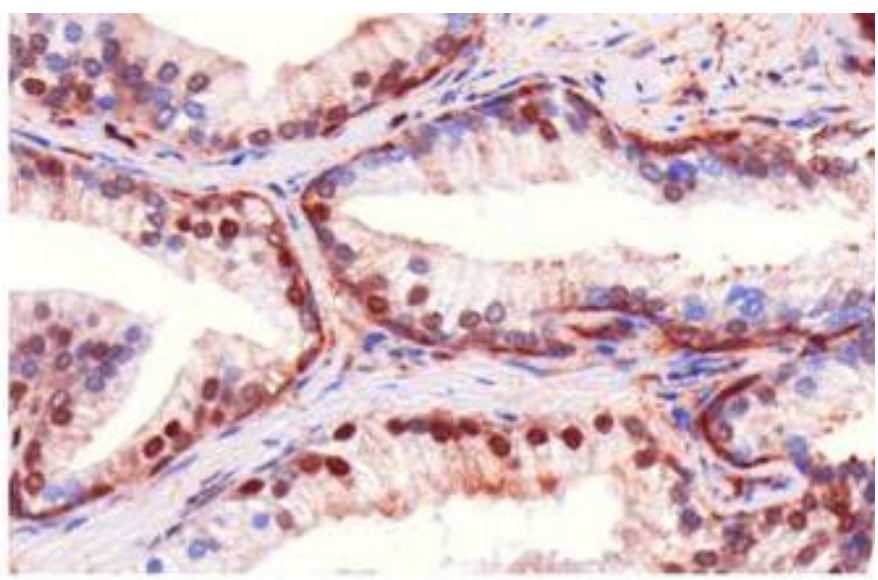

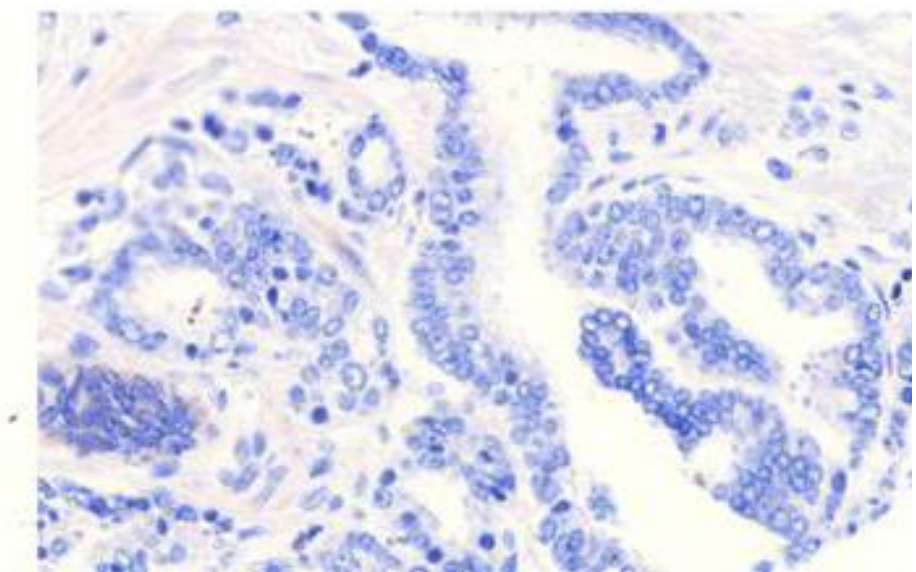

Fig. (1). Representative staining results of normal (A) and malignant (B) prostate tissue at a magnification of 7x (left image) and 40x (right image). 
Table 1. Clinicopathological Parameters of Patients with Prostate Cancer and Benign Prostate Tissue.

\begin{tabular}{|c|c|c|}
\hline & Prostate Cancer $n=73$ & Normal Prostate $N=14$ \\
\hline range & $57-91$ & $57-79$ \\
\hline \multicolumn{3}{|l|}{ Serum PSA level } \\
\hline $4-10 \mathrm{ng} / \mathrm{ml}$ & $33(45.2 \%)$ & $9(64.3 \%)$ \\
\hline$>10 \mathrm{ng} / \mathrm{ml}$ & $31(42.5 \%)$ & $2(14.3 \%)$ \\
\hline \multicolumn{3}{|l|}{ Pathological Stage } \\
\hline pT2 & $44(60.3 \%)$ & n.a. \\
\hline capsular Infiltration & $42(57.5 \%)$ & n.a. \\
\hline seminal vesicle invasion & $9(12.3 \%)$ & n.a. \\
\hline lymph node metastasis & $6(8.2 \%)$ & n.a. \\
\hline \multicolumn{3}{|l|}{ Gleason Score } \\
\hline$<=6$ & $28(38.4 \%)$ & n.a. \\
\hline 7 & $17(23.3 \%)$ & n.a. \\
\hline$>=8$ & $28(38.4 \%)$ & n.a. \\
\hline
\end{tabular}

Abbreviation: n.a., not applicable

Table 2. Correlations of Pdcd4 Staining and Clinicopathological Parameters as Determined Using the Chi-square Test.

\begin{tabular}{|l|c|c|c|c|c|}
\hline & Cytoplasm Positive & Cytoplasm Score & Nucleus Positive & Nucleus Quantity & Nucleus Intensity \\
\hline \hline Cancer vs. benign & $\mathrm{P}=0.034$ & $\mathrm{P}=0.104$ & $\mathrm{P}<0.001$ & $\mathrm{P}<0.001$ & $\mathrm{P}<0.001$ \\
\hline pT-stage & $\mathrm{P}=0.157$ & $\mathrm{P}=0.348$ & $\mathrm{P}=0.333$ & $\mathrm{P}=0.637$ & $\mathrm{P}=0.564$ \\
\hline Lymph node metastasis & $\mathrm{P}=0.166$ & $\mathrm{P}=0.464$ & $\mathrm{P}=0.226$ & $\mathrm{P}=0.812$ & $\mathrm{P}=0.812$ \\
\hline Gleason Score & $\mathrm{P}=0.235$ & $\mathrm{P}=0.400$ & $\mathrm{P}=0.558$ & $\mathrm{P}=0.404$ & $\mathrm{P}=0.125$ \\
\hline PSA & $\mathrm{P}=0.644$ & $\mathrm{P}=0.882$ & $\mathrm{P}=0.363$ & $\mathrm{P}=0.161$ & $\mathrm{P}=0.656$ \\
\hline
\end{tabular}

nuclear and cytoplasmatic staining quantity were $15.6 \%$ and $62.6 \%$ in prostate cancer tissue compared to $83.6 \%$ and 93.3\% in benign prostate tissue (see Fig. 2): Overall Pdcd4 levels were lower in prostate cancer tissue, however, only $\operatorname{Pdcd} 4$ positivity reached significance $(p=0.034)$, whereas the difference concerning the Pdcd4 score did not reach significance $(\mathrm{p}=0.104)$. The different nuclear staining pattern allowed to distinguish malignant and benign prostate tissue as determined using receiver operator characteristic analyses: Nuclear quantity reached a specificity of $92.1 \%$ and a sensitivity of $14.3 \%$ (AUC: 0.783 , CI: $0.657-0.908$ ) and nuclear intensity reached a specificity of $81.6 \%$ and a sensitivity of $74.4 \%$ (AUC: 0.802 , CI: $0.676-0.928$ ), whereas Pdcd4 staining reached a specificity of $30.3 \%$ and a sensitivity of $92.9 \%$ (AUC: 0.616, CI: 0.472-0.759).
We next investigated whether Pdcd4 expression was correlated with adverse clinicopathological parameters. Neither preoperative PSA levels, pathological staging nor Gleason Score were correlated with nuclear or cytoplasmic Pdcd4 expression (all p>0.1), although there was a trend towards lower Pdcd4 levels in locally-advanced and lessdifferentiated prostate cancers. Pdcd4 staining results did not significantly influence cancer specific survival $(\mathrm{p}=0.132, \mathrm{CI}$ : 48.58-86.35) in our cohort.

\section{DISCUSSION}

In this study, we demonstrate that the tumor suppressor gene Pdcd4 is downregulated in prostate cancer tissue. Interestingly, the nuclear and cytoplasmic Pdcd4 expression is different: while nuclear Pdcd4 is steadily downregulated in 

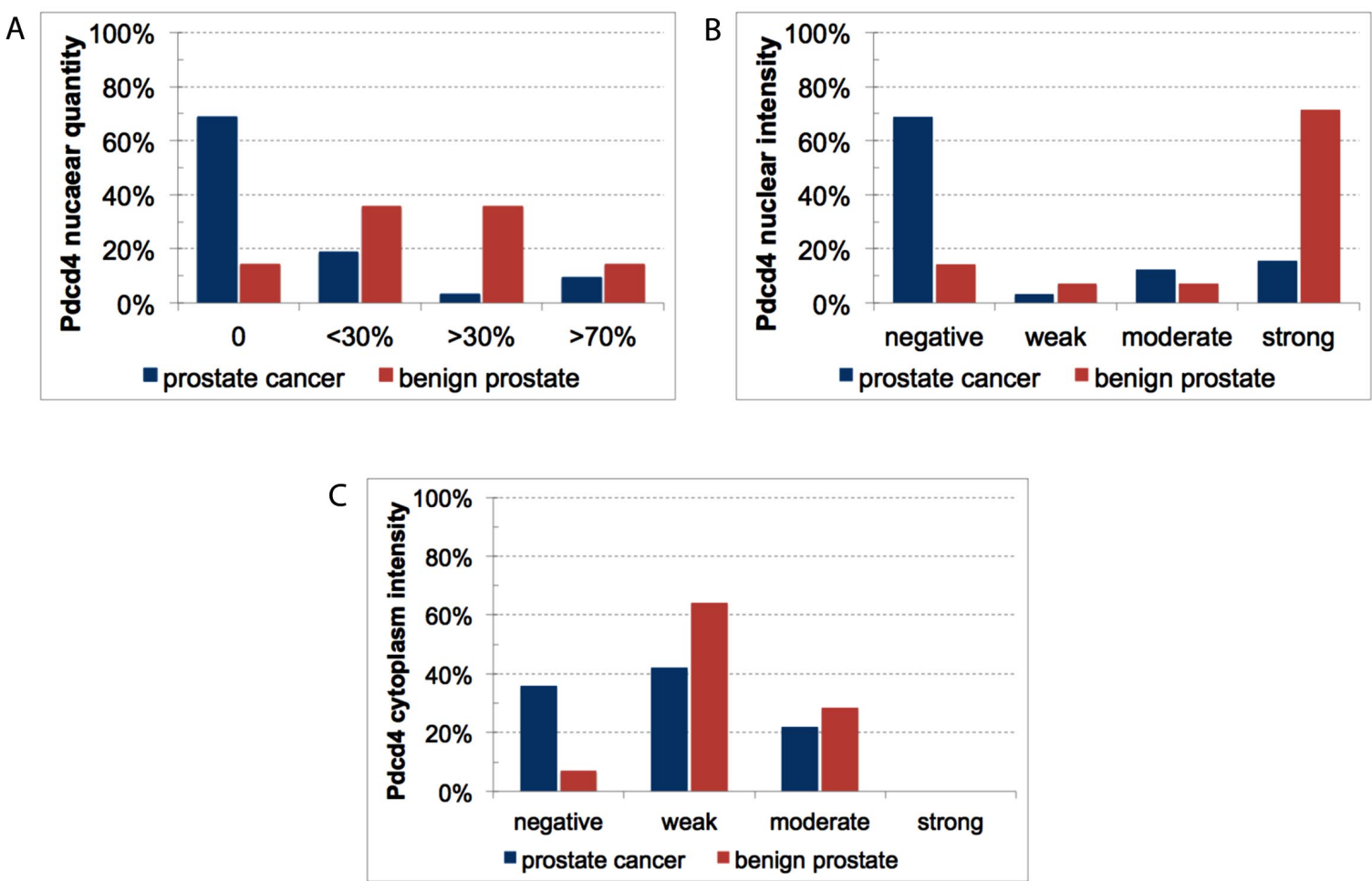

Fig. (2). Distribution of nuclear (A,B) and cytoplasmatic (C) staining in malignant and benign prostate tissue.

tumor cells, the cytoplasmic staining is less different in cancerous and non-malignant cells. These findings are in good agreement with the report of Göke et al., who demonstrated Pdcd4 downregulation in seven prostate cancer tissue samples earlier [7]. The loss of Pdcd4 in most prostate cancer samples and the finding of similar levels in patients with good and adverse prognosis indicates that Pdcd4 expression changes occur early during prostate carcinoge nesis. Göke et al. also demonstrated that Pdcd4 induced the expression of the (CDK)1/cdc2 cyclin-dependent kinase inhibitor p21Waf1/Cip1[7]. These findings indicate that Pdcd4 acts as tumor suppressor gene. Targeting Pdcd4 could be a future therapeutic option: In a lung cancer mice model, aerosol delivery of a Pdcd4-complex induced apoptosis and inhibited pathways for cell proliferation and tumor angiogenesis [8].

Earlier studies indicated that Pdcd4 expression is controlled by microRNAs: Davis et al. demonstrated that TGF-beta induced the expression of mature miR-21 in smooth muscle cells; miR-21 in turn suppressed the Pdcd4 levels [9]. A conserved target site for miR-21 is located in the 3 'UTR of the Pdcd 4 mRNA. Thus, transfection of miR21 lead to a decrease of Pdcd4. Thereby, miR-21 expression causes invasion, intravasation and metatstasis in a chickenembryo-metastasis assay and in glioblastoma cells $[3,10]$. In an earlier study on urothelial carcinoma of the bladder, we found increased miR-21 levels with a suppression of Pdcd4 expression [11].

Pdcd4 may represent a target for future medical therapy in all prostate cancer patients. Shiota et al. showed that Pdcd4 interacts with the DNA binding domain of the transcription factor Twist1, inhibiting its DNA binding ability and Y-box binding protein-1 (YB-1) expression, and thereby reduces cell growth [12]. Restoration of Pdcd4 expression was associated with an increased sensitivity to cisplatin and paclitaxel chemotherapy in prostate cancer cell lines (PC3) [12].

\section{CONCLUSION}

Our study indicates an important role for Pdcd4 downregulation during prostate carcinogenesis, and Pdcd4 expression differences in normal and malignant tissue may be of diagnostic value, especially when therapeutic aspects of Pdcd4 expression modulation are currently being evaluated.

\section{CONFLICT OF INTEREST}

The authors disclose any conflict of interest.

\section{ACKNOWLEDGEMENTS}

We thank Mrs. Doris Schmidt and Mrs. Susanne Steiner for technical assistance.

\section{REFERENCES}

[1] Yang HS, Jansen AP, Komar AA, et al. The transformation suppressor Pdcd4 is a novel eukaryotic translation initiation factor 4A binding protein that inhibits translation. Mol Cell Biol 2003; 23: 26-37.

[2] Yang HS, Jansen AP, Nair R, et al. A novel transformation suppressor, Pdcd4, inhibits AP-1 transactivation but not NFkappaB or ODC transactivation. Oncogene 2001; 20: 669-76. 
[3] Asangani IA, Rasheed SA, Nikolova DA, et al. MicroRNA-21 (miR-21) post-transcriptionally downregulates tumor suppressor Pdcd4 and stimulates invasion, intravasation and metastasis in colorectal cancer. Oncogene 2008; 27: 2128-36.

[4] Lankat-Buttgereit B, Gregel C, Knolle A, Hasilik A, Arnold R, Goke R. Pdcd4 inhibits growth of tumor cells by suppression of carbonic anhydrase type II. Mol Cell Endocrinol 2004; 214: 14953.

[5] Leupold JH, Yang HS, Colburn NH, Asangani I, Post S, Allgayer H. Tumor suppressor Pdcd4 inhibits invasion/intravasation and regulates urokinase receptor (u-PAR) gene expression via $\mathrm{Sp}$ transcription factors. Oncogene 2007; 26: 4550-62.

[6] Nieves-Alicea R, Colburn NH, Simeone AM, Tari AM. Programmed cell death 4 inhibits breast cancer cell invasion by increasing tissue inhibitor of metalloproteinases-2 expression. Breast Cancer Res Treat 2009; 114: 203-9.

[7] Goke R, Barth P, Schmidt A, Samans B, Lankat-Buttgereit B. Programmed cell death protein 4 suppresses CDK1/cdc2 via induction of p21(Waf1/Cip1). Am J Physiol Cell Physiol 2004; 287: C 1541-46.
[8] Jin H, Kim TH, Hwang SK, et al. Aerosol delivery of urocanic acid-modified chitosan/programmed cell death 4 complex regulated apoptosis, cell cycle, and angiogenesis in lungs of K-ras null mice. Mol Cancer Ther 2006; 5:1041-9.

[9] Davis BN, Hilyard AC, Lagna G, Hata A. SMAD proteins control DROSHA-mediated microRNA maturation. Nature 2008; 454: 5661 .

[10] Gaur AB, Holbeck SL, Colburn NH, Israel MA. Downregulation of Pdcd4 by mir-21 facilitates glioblastoma proliferation in vivo. Neuro Oncol 2011; 13: 580-90.

[11] Fischer N, Goke F, Splittstosser V, Lankat-Buttgereit B, Muller SC, Ellinger J. Expression of programmed cell death protein 4 (Pdcd4) and miR-21 in urothelial carcinoma. Biochem Biophys Res Commun 2012; 417: 29-34.

[12] Shiota M, Izumi H, Tanimoto A, et al. Programmed cell death protein 4 down-regulates Y-box binding protein-1 expression via a direct interaction with Twist1 to suppress cancer cell growth. Cancer Res 2009; 69: 3148-56.

Received: October 12, 2013

Revised: December 18, 2013

Accepted: December 19, 2013

(C) Fischer et al.; Licensee Bentham Open.

This is an open access article licensed under the terms of the Creative Commons Attribution Non-Commercial License (http://creativecommons.org/licenses/ by-nc/3.0/) which permits unrestricted, non-commercial use, distribution and reproduction in any medium, provided the work is properly cited. 